\title{
Voluminous Storage and Rapid Magma Ascent Beneath La Palma Revealed by Seismic Tomography
}

\section{Luca D'Auria}

Instituto Volcanológico de Canarias

Ivan Koulakov

Novosibirsk State University

Janire Prudencio

University of Granada

Ivan Cabrera-Perez

Instituto Volcanológico de Canarias

Jesus Ibanez ( $\nabla_{\text {jibanez@ugr.es })}$

University of Granada

Jose Barrancos Martinez

Instituto Volcanológico de Canarias

Ruben Garcia-Hernandez

Instituto Volcanológico de Canarias

David Martinez van Dorth

Instituto Volcanológico de Canarias

German Padilla Hernandez

Instituto Volcanológico de Canarias

Monika Przeor

Instituto Volcanológico de Canarias

Victor Ortega

Instituto Volcanológico de Canarias

Pedro Hernandez Perez

Instituto Volcanológico de Canarias

Nemesio Perez Rodriguez

Instituto Volcanológico de Canarias

\section{Research Article}

Keywords: Rapid Magma, Seismic Tomography, magmatic plumbing systems

Posted Date: January 13th, 2022 
DOI: https://doi.org/10.21203/rs.3.rs-1238072/v1

License: (c) (1) This work is licensed under a Creative Commons Attribution 4.0 International License. Read Full License 


\section{Abstract}

Seismic tomography provides a window into magmatic plumbing systems; however, obtaining sufficient data for 'real-time' imaging is challenging. Until now, syn-eruptive tomography has not been successfully demonstrated. For the first time, we obtained high-resolution images of Earth's interior during an ongoing volcanic eruption. We used data from 11,349 earthquakes, most of which during La Palma eruption (19 September-13 December, 2021), to perform travel-time seismic tomography. We present high-precision earthquake relocations and $3 \mathrm{D}$ distributions of $\mathrm{P}$ and $\mathrm{S}$-wave velocities highlighting the geometry of magma sources. We identified three distinct structures: (1) a shallow localised region $(<3 \mathrm{~km})$ of hydrothermal alteration; (2) spatially extensive, consolidated, oceanic crust extending to $10 \mathrm{~km}$ depth and; (3) a large ( $>400 \mathrm{~km}^{3}$ ) sub-crustal magma-filled rock volume intrusion extending from $\sim 7$ to $25 \mathrm{~km}$ depth. Our results suggest that this large magma reservoir feeds the La Palma eruption continuously for almost three months. Prior to eruption onset, magma ascended from $\sim 10 \mathrm{~km}$ depth to the surface in $<7$ days. In the upper $3 \mathrm{~km}$, melt migration is along the western contact between consolidated oceanic crust and altered hydrothermal material. Similar structural weaknesses along the eastern contact could potentially cause new eruptive centres in the future.

\section{Introduction}

Volcano seismology remains one of the most important tools for volcano monitoring. As one of its most significant developments, seismic tomography provides a window into sub-surface structures and their links to magmatic processes ${ }^{1,2}$. However, obtaining tomographic images during eruptions is complex owing to the requirement of high numbers of seismic stations and earthquakes with adequate spatiotemporal distributions to provide sufficient resolution. Until now, researchers have struggled to perform syn-eruptive tomography, even at intensively monitored volcanoes with persistent activity.

On 19 September 2021, an eruption of high social and scientific impact began on the island of La Palma, Canary Islands, Spain (Fig. 1) and lasted for almost three months until 13 December 2021. To date there have been no casualties, but the eruption has destroyed thousands of homes, disrupted transport and communication networks, and affected extensive areas of farmland that are key to the local economy. Media interest has been high. In less than three months, this fissure eruption formed a lava field of $>12$ $\mathrm{km}^{2}$ with thicknesses of up to tens of meters. Among seven previous eruptions on La Palma in the last 500 years $^{3}$, the largest formed a lava field of just $4.4 \mathrm{~km}^{2}$ (Fig. 1). The eruptive style has been mainly effusive, but with numerous Strombolian explosions and partial collapses of the cone. Intense and unusual seismicity activity before and during the eruption has included earthquakes with high magnitudes for this volcano type (up to $\mathrm{Ml}=4.3$ ). The released seismic strain of intermediate seismicity (5-10 km) is almost $4 \times$ larger than that of deep and shallow seismicity, suggesting that stress generation in this region is dominating the eruptive process (Extended Data Figure 5). One of the most important characteristics of this seismicity is the difference between pre-eruptive and syn-eruptive seismicity. The pre-eruptive seismicity is of low magnitude and shows evident migrations from the deep 
towards the surface (Fig. 1). The syn-eruptive seismicity is of much larger magnitude and presents two focal depth clusters, 10-12 km depth and 20-25 km depth with no apparent migration (Fig. 1).

Owing to effective cooperation between different scientific institutions, for the first time, we obtained high-resolution 3D tomographic images of Earth's interior during the eruptive process (from the first seismic unrest -December 2017- to the present period of eruptive calm occurred on December 13, 2021). Our results have great scientific and social impact and offer improved understanding of pre- and syneruptive activity, along with the possible future volcanic scenarios in La Palma Island.

(1) The Canary Islands, including La Palma, are underlain by high-velocity oceanic crust. Beneath most islands, the Moho (i.e., the base of the oceanic crust) is at $\sim 10-12 \mathrm{~km}$ below sea level (bsl); this depth is greater than that between and surrounding the islands and is the expected consequence of isostatic equilibrium ${ }^{6-10}$. However, unlike the neighbouring island of El Hierro, where a volcanic unrest was observed in 2012, there is no crustal thickening beneath La Palma. On the contrary, our tomographic images suggest crustal thinning, with a high-velocity body extending from $\sim 8$ to $10 \mathrm{~km}$ bsl.

(2) Underlying the volcanically active sector of La Palma is a spatially limited high Vp/Vs ( $>2$ ) and low velocity ( $\mathrm{Vp}$ and $\mathrm{Vs}>10 \%$ below the average) structure extending from the surface to $\sim 3 \mathrm{~km}$ bsl. This structure has previously been identified as a high-resistivity hydrothermal zone ${ }^{11}$.

(3) The third structure, characterised by elevated Vp, very low Vs (> 10\% below the mean), and high Vp/Vs (> 2.05), extends between 7 and $25 \mathrm{~km}$ bls beneath the volcanically active sector of La Palma and represents partially molten material pooled th the base of oceanic crust. Based on our tomographic images, upward bending of the Moho, very high rates of seismicity, and gas emissions (e.g., $\left.\mathrm{SO}_{2}\right)^{12}$, we estimate the volume of this magma-filled rock volume to be at least $400 \mathrm{~km}^{3}$, dwarfing the other structures resolved by tomography.

\section{Eruptive Model}

Based on earthquake relocations and our 3D tomographic images, we developed a model of the ongoing volcanic activity on La Palma (Fig. 3).

(1) For 2 million years, repeated accumulations of magma have deformed the base of the oceanic crust beneath La Palma ${ }^{13}$, as evidenced by upward displacement of the Moho and the shape of tomographic structures. Between December 2017 and August 2021, at least 9 earthquake swarms (producing 700 well-located earthquakes) recorded magma injections from the mantle to the base of the oceanic crust beneath Cumbre Vieja volcano (the locus of all historical eruptions, including the present activity), causing the accumulation of a large $\left(>400 \mathrm{~km}^{3}\right)$ magma-filled rock volume (Fig. 3a). This process, although likely continuous, did not cause significant stress changes, as evidenced by the sporadic and low-magnitude seismicity $(\mathrm{Ml}<2.0)$, suggesting the presence of pre-established ascent pathways. This is consistent with observations of magmatic differentiation ${ }^{14}$, a process that requires time. Initial 
earthquakes delineate the upper limit of the reservoir (i.e., the Moho or lower limit of consolidated oceanic crust). The foci of later precursory events trace fluid migration towards the surface and the exchange of stress with consolidated oceanic crust in the months before the eruption (Figure 3a and Extended Data figures 5-11).

(2) After a month of seismic quiescence, in the 7 days before eruption onset (14:00 UTC on 19 September), magma ascended rapidly from $10 \mathrm{~km}$ bsl (i.e., the base of the Moho) to the surface along a zone of structural weakness delineated by a low velocity tomographic anomaly associated with seismicity that occurred a few months earlier (Figure 2, Extended Data figures 9-11). For the first $3 \mathrm{~km}$, this low-velocity anomaly is vertical, but close to the surface it follows a NNE-SSE trend and dips $~ 30$ degrees towards the current eruptive centre. The migration of seismicity in the shallow crust follows the western boundary of consolidated oceanic crust and the hydrothermally altered zone. Despite the highly fractured and brittle nature of the hydrothermal zone, which theoretically offers low resistance to magma ascent, we hypothesise that the contact zone must present even lower mechanical resistance, which is consistent with the small magnitudes of earthquakes in the hours before the eruption (Fig. 3b).

Interestingly, tomographic images indicate similar structural weaknesses along the eastern contact zone; a change in the pressure state of the magma could potentially open new eruptive centres associated with this eastern sector (Figure 2, Extended Data figures 9-11).

(3) Seismicity during the first few days of eruption was characterised by energetic volcanic tremor. However, on 29 September, 10 days after eruption onset, an intense seismic swarm (in which most events had magnitudes of $\mathrm{Ml}>3.0$ ) occurred along the contact between the magmatic body and lower limit of the oceanic crust $(\sim 10 \mathrm{~km})$. This seismicity, which is ongoing just until reaching the current period of eruptive calm on December 13,2021, can be explained by the collapse of brittle crustal material above the reservoir owing to the continuous extraction of magma to the surface as schematically shown in Figure 3c. In addition, since early October, a new earthquake cluster $(\mathrm{Ml}>3.0)$ has been observed at 17$30 \mathrm{~km}$ depth (Fig. 1). This deeper seismicity, which shows no preferential lineation or temporal migration, includes the highest earthquake magnitudes recorded to date (up to $\mathrm{Ml}=4.3$ ) and is located above a deep upper-mantle magma reservoir (close to the lithosphere base), as reported by previous studies ${ }^{15,16}$. We attribute this cluster to two possible explanations. (1) Magma compression caused by the collapse of crustal material had a piston effect; increased pressure at 12-15 km pushed magma both upwards and downwards (Fig. 3c). The opposing force of magma ascending from the mantle created excessive pressure in the conduit between the upper and lower reservoirs, which triggered fracturing of rocks around the conduit. (2) Alternatively, by invoking stress propagation model similar to that of the 2011-2014 eruption of neighbouring El Hierro ${ }^{17}$, this activity could record the collapse of magmatic conduits owing to magma withdrawal and corresponding depressurization.

Our syn-eruptive tomographic images mark a milestone in the field of volcano seismology, and provide valuable insight into the short-term evolution of a magma plumbing system from the upper mantle to the surface. In particular, given the large size of the magma reservoir that feeds the volcanic eruption it is not 
possible to discard this magmatic system could cause future new volcanic eruptions on the Island of La Palma.

\section{Methods}

\section{Data}

In this study, we merged datasets derived by the two governmental agencies operating on La Palma prior to and during the eruption: the Instituto Geográfico Nacional (IGN; 11 stations) and the Instituto Volcanológico de Canarias (INVOLCAN; 12 stations). Both datasets cover the time span from 7 October 2017 to 13 December 2021. When merging, we assumed that both agencies had recorded the same event if the difference between the origin times in the provided solutions was $<1 \mathrm{~s}$. The merged dataset contains 13,681 events recorded on 23 stations, with 140,078 P wave and 155,231 S wave picks. Event magnitudes were based on solutions provided by INVOLCAN using the MI magnitude scale.

\section{Tomographic inversion}

Tomographic inversion was based on the local earthquake tomography code LOTOS $^{18}$, which has been used to investigate dozens of different volcanoes ${ }^{9,19-22}$. First, event locations in the reference 1D velocity model are determined using a grid-search method and linear approximation of ray paths ${ }^{9}$. We used the topography surface to limit the depths of events; therefore, events can be located above the sea surface. During this step, we selected events with eight or more picks and removed all data with absolute residual values of $>0.5 \mathrm{~s}$ for $\mathrm{P}$ waves and 0.7 for $\mathrm{S}$ waves. After removing outliers, the dataset used for the tomographic procedure included 11,349 events with $121,572 \mathrm{P}$ wave and $127,766 \mathrm{~S}$ wave arrival times (mean of 22 picks per event).

Next, we relocated event sources using the gradient method and 3D bending algorithm for ray tracing ${ }^{9}$. In the first iteration, the relocation was conducted in the starting 1D model; in subsequent iterations, calculations were performed in the updated 3D model.

The 3D distributions of $\mathrm{P}$ and $\mathrm{S}$ wave velocity anomalies were parameterised using grid nodes irregularly distributed in the study area according to the ray density. Between the nodes, velocities were approximated continuously using bi-linear interpolation. The minimum grid spacing in both the horizontal and vertical directions was $0.7 \mathrm{~km}$, which is considerably smaller than the size of resolved anomalies in our model. To reduce the influence of parameterisation on the results, we performed inversions in four grids with different basic orientations to the azimuthal direction $(0,22,45$, and 67 degrees) and then averaged them into one regular grid.

The inversion was performed simultaneously for the $\mathrm{P}$ and $\mathrm{S}$ velocity anomalies, source parameters ( $\mathrm{dx}$, $\mathrm{dy}, \mathrm{dz}$, and dt), and station corrections. To stabilise the solutions, we used two types of regularisationamplitude damping and flattening-which were performed by adding the corresponding equations to the general system. The values of the damping coefficients were determined from a series of synthetic tests 
with realistic anomaly sizes and noise levels. The derived sparse matrix was inverted using the LSQR method $^{23,24}$.

After inversion in the four grids, the resulting $P$ and $S$ wave velocity anomalies were recalculated in a regular grid and then used for the next iteration, which included source relocation, matrix calculation, and inversion. In total, for the experimental and synthetic data, we performed five iterations, which was a compromise between solution stability and calculation velocity. The calculations enabled considerable variance reduction. In the $\mathrm{L} 1$ norm, the average $\mathrm{P}$ wave residuals reduced from 0.2397 to $0.0860 \mathrm{~s}$ $(64.12 \%)$ and those for $\mathrm{S}$ waves reduced from 0.3058 to $0.1401 \mathrm{~s}(54.17 \%)$.

Extended Data Figure 1 and 2 show the inversion results of experimental data, including horizontal and vertical sections of $\mathrm{Vp} / \mathrm{Vs}, \mathrm{P}$ wave velocity, and $\mathrm{S}$ wave velocity anomalies. In the context of magmarelated structures, it is important to present the $\mathrm{Vp} / \mathrm{Vs}$ ratio, which was calculated by division of the derived $\mathrm{P}$ and $\mathrm{S}$ absolute velocities. The adequacy of this method was determined by the similar volumes of $P$ and $S$ wave data, and was confirmed using synthetic tests.

The optimal 1D reference velocity model was derived after several runs of the complete tomographic procedure. After each trial, we calculated the average $P$ and $S$ velocities at certain depths and used them for the next iteration. As a result, we obtained a fair balance between high- and low-velocity anomalies at all depth layers.

To access the spatial resolution of the resulting models and to derive optimal values of controlling parameters for the tomographic procedure, we performed a series of synthetic tests. In all cases, the synthetic model was defined by a set of positive and negative anomalies with respect to the a priori 1D reference model. Synthetic travel times were calculated for the same source-receiver pairs as derived in the main experimental model after five iterations. The derived data were perturbed by random noise with an average deviation of $0.03 \mathrm{~s}$ for both $\mathrm{P}$ and $\mathrm{S}$ data, which enabled the same variance reduction as in the experimental data inversion. Before starting the synthetic model recovery, we "forgot" any information about the sources. Then, calculations were performed based on the same workflow as in the experimental data processing, including source location in the starting 1D model using the grid-search method. During synthetic modelling, we tuned the values of the controlling parameters to derive an optimal quality of the initial model recovery; then, the same controlling parameters were used for the experimental data inversion.

We separately investigated the resolution in the horizontal and vertical directions. In the first series of tests, we defined several checkerboard models with different anomaly sizes in map view. In Extended Data Figure 1, we present three tests with anomalies of 2, 3, and $4 \mathrm{~km}$ separated by $1 \mathrm{~km}$ spacing with zero anomaly values. In all cases, the amplitudes of anomalies were $\pm 8 \%$. We defined the opposite signs of the $d V p$ and $d V s$ anomalies to enable contrasted variations of the $V p / V s$ ratio. The recovery results are presented in two depth sections. Anomalies of $2 \mathrm{~km}$ in size were only resolved in the central part of the study area, where most earthquakes were located. For the models with larger anomalies, fair resolution 
was observed in most parts of the study area. Based on the results of these tests, we defined a contour of the resolved area, in which the results of experimental data were plotted (Extended Data Figure 1-3). From these tests, we confirmed that the distribution of $\mathrm{Vp} / \mathrm{Vs}$ was correctly recovered, demonstrating the adequacy of the method for this parameter calculation.

In another series of tests, we explored the vertical resolution. Regarding the trade-off between velocity and source coordinates in passive source tomography, as well as dominantly vertical orientations of ray paths, we could expect poorer vertical resolution compared with horizontal resolution. In particular, there was a concern about the capacity of the existing data to provide abrupt changes in velocity at $\sim 10 \mathrm{~km}$ depth, as observed in the experimental data inversion. To address this problem, we defined models with alternated anomalies defined in each of the vertical sections in which the main results are presented. Along these sections, the anomalies had a size of $4 \mathrm{~km}$ and a spacing of $2 \mathrm{~km}$. In the vertical direction, they formed two rows with an interval of zero values at depths between 6 and $10 \mathrm{~km}$. This test confirmed that major anomalies in the central part of the study area were correctly recovered; however, some diagonal smearing is observed in marginal regions. This effect was considered during interpretation.

As true event coordinates were presumed to be unknown in the recovery procedure, the synthetic tests allowed us to assess the accuracy of source locations. Extended Data Figure 3. Resolution test results based on the ability to solve realistic anomalies using a previous synthetic model (left column) and observing the recovery results (right column). Extended Data Figure 4 shows the mislocations of events in the model with a vertical checkerboard in section 2 with respect to the true locations. When using the starting 1D velocity model, the average error of source coordinate determination in the L1 norm was 0.69 $\mathrm{km}$. In the final model, the average error reduced to $0.38 \mathrm{~km}$. As expected, the maximum errors were observed for events on the periphery of the network and at the greatest depths. These errors do not significantly affect the interpretation of the results presented in this manuscript.

\section{Declarations}

\section{Data and code availability}

The seismic catalogue of IGN is publically available at: https://www.ign.es/web/ign/portal/sis-catalogoterremotos. The seismic catalogue of INVOLCAN is available under request to Dr. Luca D'Auria (Idauria@iter.es). The LOTOS code is publically available at: www.ivan-art.com/science/LOTOS

\section{Acknowledgements}

JP and JMI were partially supported by the FEMALE project of the Spanish Government (Grant No. PID2019-106260GB-I00). IK was supported by the Russian Science Foundation (Grant No. 20-17-00075). The INVOLCAN team was supported by the projects VOLRISKMAC II (MAC2/3.5b/328), co-financed by the EC Cooperation Transnational Program MAC 2014-2020, and TERMOVOLCAN (RTC-2017-6627-3), cofinanced by the Spanish National R\&D plan. English language editing was performed by Tornillo Scientific, UK. 


\section{Author contributions}

Luca D’Auria: Compilation of seismic databases; seismic data acquisition; figure and map creation; discussion of final models; manuscript writing.

Ivan Koulakov: Seismic tomography; figure creation; discussion of final models; manuscript writing.

Janire Prudencio: Figure creation; discussion of final models; manuscript writing.

Iván Cabrera-Pérez: Compilation of seismic databases; seismic data acquisition;

figure creation; manuscript writing.

Jesús M. Ibáñez: Coordinator of the research team; discussion of final models; manuscript writing.

Jose Barrancos; Rubén García-Hernández; David Martínez van Dorth; Germán D. Padilla; Monika Przeor, and Victor Ortega: Seismic data aquisition.

Pedro Hernández and Nemesio M. Peréz: Coordination of funds to acquire seismic databases; coordinators of the INVOLCAN working team

\section{Competing interest declaration}

The authors declare no competing interests.

\section{Additional information}

Supplementary Information is available for this paper.

Correspondence and requests for materials should be addressed to Jesús M. Ibáñez (University of Granada, Spain; jibanez@ugr.es)

Reprints and permissions information is available at www.nature.com/reprints.

\section{References}

1. Lees, J. M. Seismic tomography of magmatic systems. J. Volc. Geotherm. Res. 167(1-4), 37-56 (2007).

2. Koulakov, I. \& Shapiro, N. Seismic tomography of volcanoes. Encyclopedia of Earthquake Engineering, 3117-3134 (Springer, Dordrecht, 2015).

3. Ancochea, E., et al. Constructive and destructive episodes in the building of a young oceanic island, La Palma, Canary Islands, and genesis of the Caldera de Taburiente. J. Volc. Geotherm. Res. 60(34), 243-262 (1994). 
4. Torres-González, P. A. et al. Unrest signals after 46 years of quiescence at Cumbre Vieja, La Palma, Canary Islands. J. Volc. Geotherm. Res. 392, 106757 (2020).

5. Fernández, J. et al. Detection of volcanic unrest onset in La Palma, Canary Islands, evolution and implications. Sci. Rep. 11(1), 1-15 (2021).

6. van der Meijde, M., van der Lee, S. \& Giardini, D. Giardini Crustal structure beneath broad-band seismic stations in the Mediterranean region. Geophys. J. Int. 152, 729-739 (2003)

7. Duggen, S. et al. Flow of Canary mantle plume material through a subcontinental lithospheric corridor beneath Africa to the Mediterranean. Geology 37, 283-286 (2009).

8. García-Yeguas, A., Koulakov, I., Ibáñez, J. M. \& Rietbrock, A. High resolution 3D P wave velocity structure beneath Tenerife Island (Canary Islands, Spain) based on tomographic inversion of activesource data. J. Geophys. Res. 117, B09309 (2012). https://doi.org/10.1029/2011JB008970

9. García-Yeguas, A. et al. Seismic tomography model reveals mantle magma sources of recent volcanic activity at El Hierro Island (Canary Islands, Spain). Geophys. J. Int. 199(3), 1739-1750 (2014).

10. Prudencio, J. et al. 3D attenuation tomography of the volcanic island of Tenerife (Canary Islands). Surv. Geophys. 36(5), 693-716 (2015). https://doi.org/10.1007/s10712-015-9333-3

11. Di Paolo, F. et al. La Palma island (Spain) geothermal system revealed by 3D magnetotelluric data inversion. Sci. Rep. 10(1), 1-8 (2020).

12. Copernicus Atmosphere Monitoring Service (CAMS). CAMS monitors transport of SO2 from La Palma volcano. https://atmosphere.copernicus.eu/cams-monitors-transport-so2-la-palma-volcano (2021).

13. Klügel, A., Hansteen, T. H., \& Schmincke, H. U. Rates of magma ascent and depths of magma reservoirs beneath La Palma (Canary Islands). Terra Nova 9(3), 117-121 (1997).

14. Pankhurst, M. J. et al. Petrology of the opening eruptive phase of the 2021 Cumbre Vieja eruption, La Palma, Canary Islands, 13 October 2021. Preprint at https://doi.org/10.21203/rs.3.rs-963593/v1 (2021).

15. Klügel, A., Schmincke, H.-U., White, J. \& Hoernle, K. A. Chronology and volcanology of the 1949 multivent rift-zone eruption on La Palma (Canary islands). J. Volc. Geotherm. Res. 94(1-4), 267-282 (1999).

16. Klügel, A., Hansteen, T. H. \& Galipp, K. Magma storage and underplating beneath Cumbre Vieja volcano, la Palma (Canary Islands). Earth Planet. Sci. Lett. 236(1-2), 211-226 (2005).

17. Díaz-Moreno, A., et al. Seismic hydraulic fracture migration originated by successive deep magma pulses: The 2011-2013 seismic series associated to the volcanic activity of El Hierro Island. J. Geophys. Res. Solid Earth120(11), 7749-7770 (2015).. https://doi.org/10.1002/2015JB012249

18. Koulakov, I. LOTOS code for local earthquake tomographic inversion: Benchmarks for testing tomographic algorithms. Bull. Seismol. Soc. Am. 99(1), 194-214 (2009). 
19. Bushenkova, N. et al. Tomographic images of magma chambers beneath the Avacha and Koryaksky volcanoes in Kamchatka. J. Geophys. Res. Solid Earth 124(9), 9694-9713 (2019).

20. Koulakov, I., Komzeleva, V., Smirnov, S. Z. \& Bortnikova, S. B. Magma-fluid interactions beneath Akutan Volcano in the Aleutian Arc based on the results of local earthquake tomography. J. Geophys. Res. Solid Earth 126(3), e2020JB021192 (2021).

21. Koulakov, I. et al. Anatomy of the Bezymianny volcano merely before an explosive eruption on 20.12. 2017. Sci. Rep. 11(1), 1-12 (2021).

22. Kuznetsov, P. Y. et al. Structure of volatile conduits beneath Gorely Volcano (Kamchatka) revealed by local earthquake tomography. Geosciences 7(4), 111 (2017).

23. Paige, C. C., \& Saunders, M. A. LSQR: An algorithm for sparse linear equations and sparse least squares. ACM Trans. Math. Soft. (TOMS) 8(1), 43-71 (1982)..

24. Nolet, G. Seismic wave propagation and seismic tomography. In Nolet, G (Ed.) Seismic tomography (pp. 1-23). Springer, Dordrecht. by D. Reidel Publishing Company (1987).

\section{Figures}



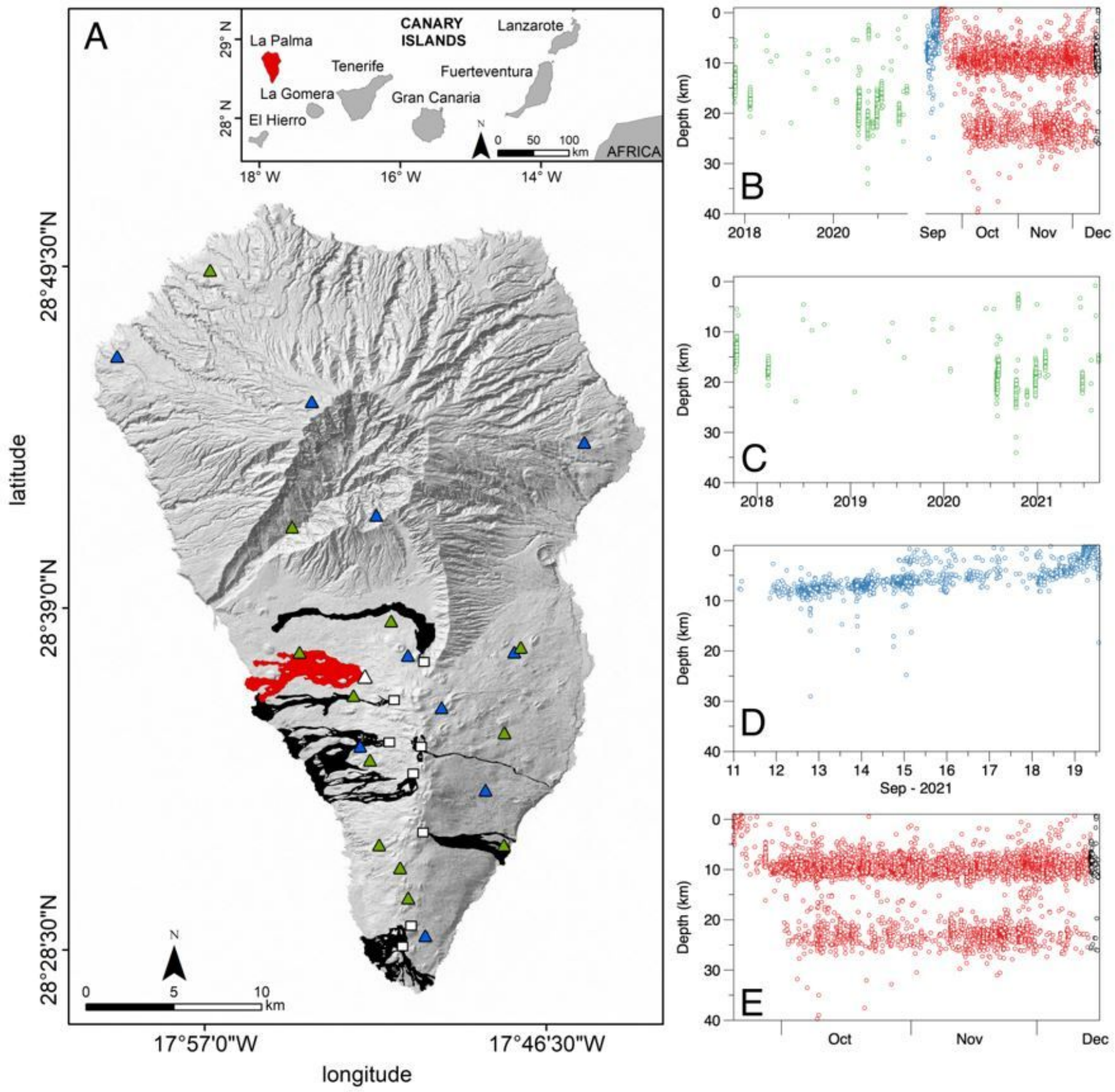

Figure 1

A) Map of La Palma island and seismic time series according to depth from late 2017 to the present (December 2021). In the map, black shading denotes lava flows from historical eruptions and red shading denotes lava flows from the on-going 2021 activity (until 20 October). B) Temporal and depth distribution of the used seismicity divided in four periods, Precursory, from 2017 to August 2021, plotted in green and zoomed in C). Pre-eruptive, the week before the start of the eruption, plotted in blue and zoomed in D). Syn-Eruptive and post-eruptive, the seismicity occurred after the start of the eruption up to December 13th 
2021 , plotted in red, and the seismicity after volcanic activity ceased, December $13-16,2021$, plotted in black.

a)
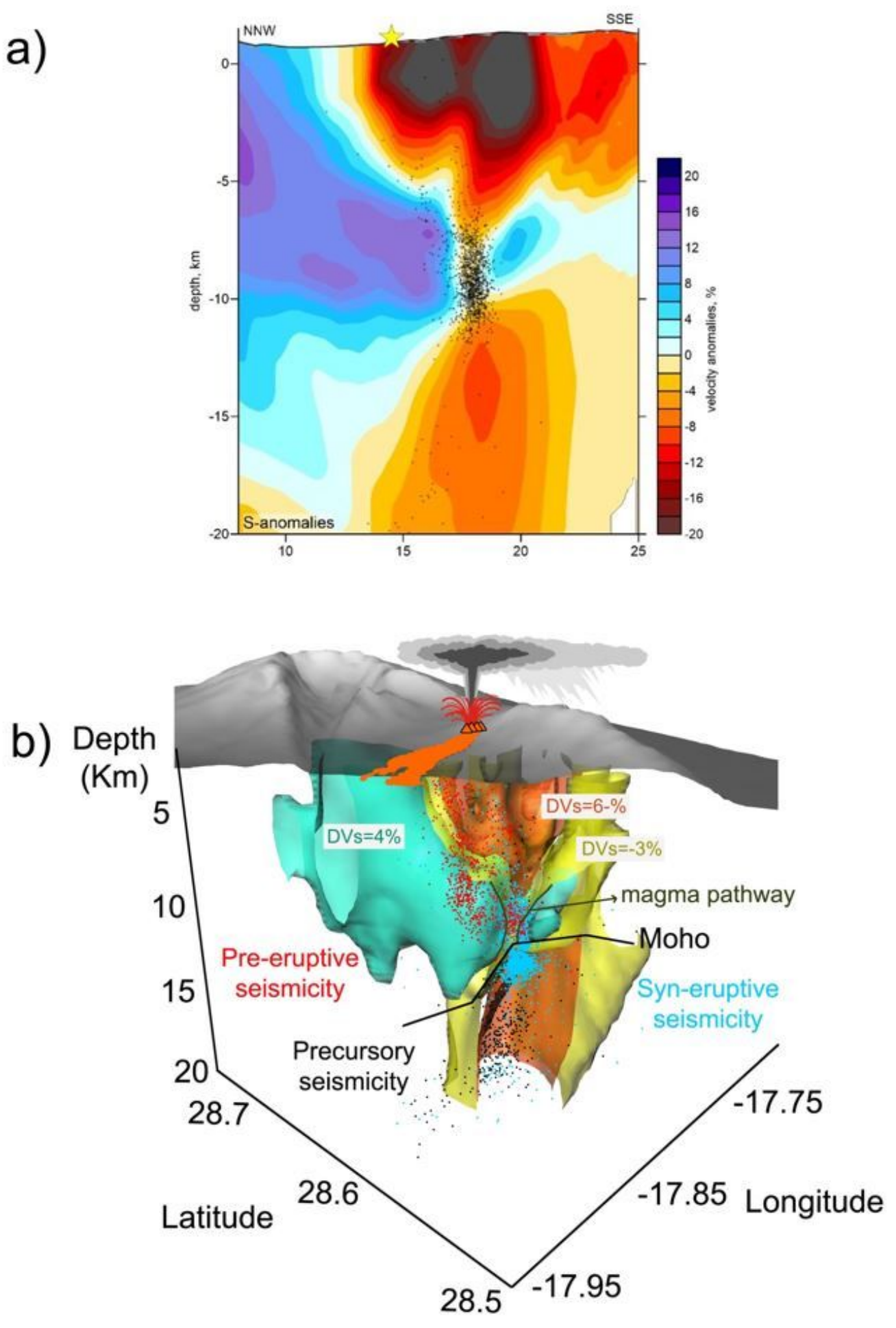

Figure 2

Seismic tomography of La Palma island from 2017 to the present (October 2021). (a) Cross section of Swaves anomalies from NNW to SSE, where black dots denote relocated seismicity; blue stars are 
projections of historical eruption vents; the yellow star is the current eruption vent. (b) Three-dimensional image representing the main structures based on $S$ waves velocity anomalies. Yellow and orange denotes bodies with lower velocity and green denotes bodies with higher velocity. The black line denotes the potential flexure of the Moho as a consequence of magma intrusion. Black dots denote pre-eruptive seismicity.
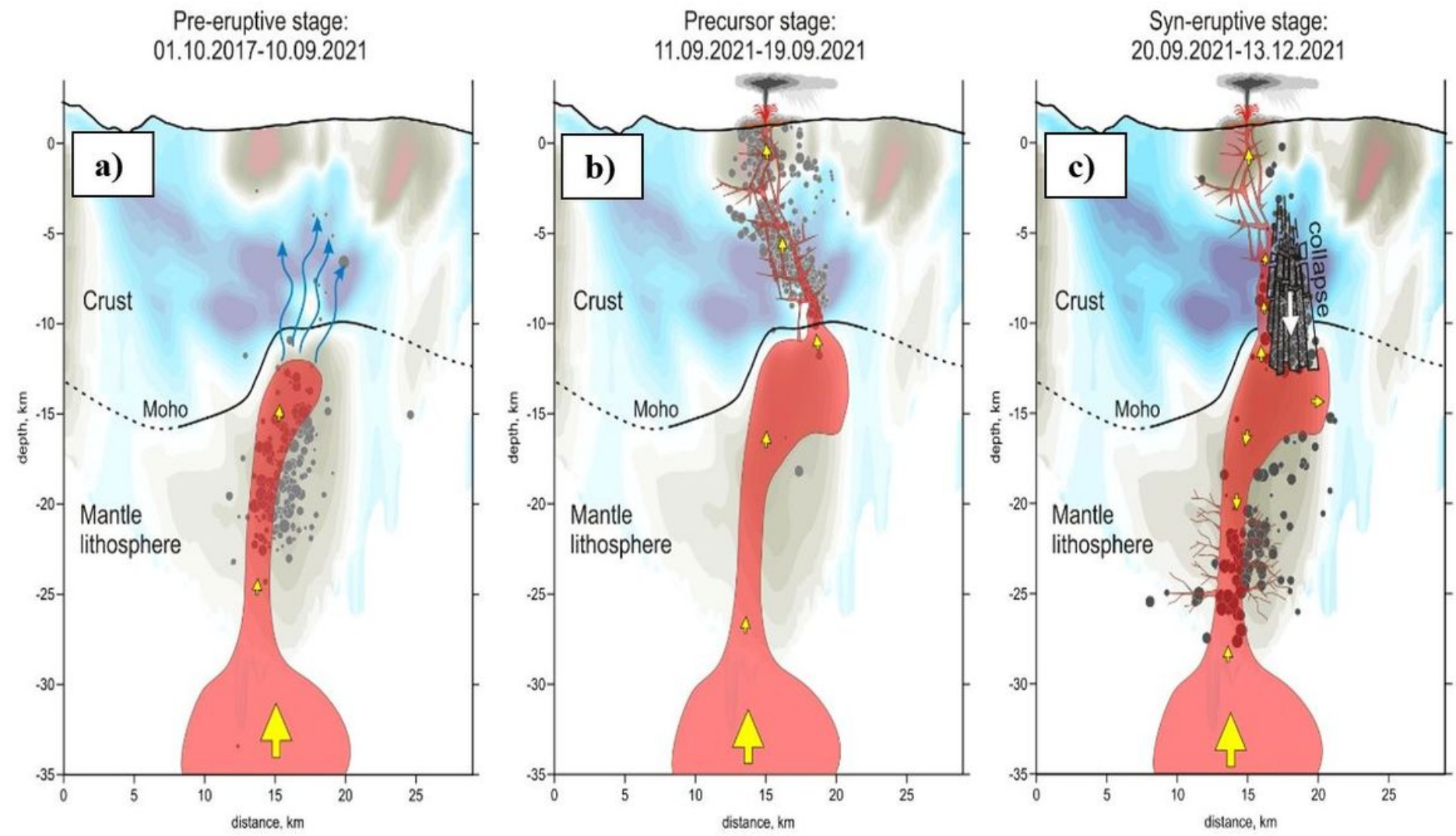

\section{Figure 3}

Model of the eruptive process preceding and accompanying the 2021 La Palma eruption. a) Pre-eruptive stage. b) Precursor stage. c) Syn-eruptive stage.

\section{Supplementary Files}

This is a list of supplementary files associated with this preprint. Click to download.

- SEISMICTOMOGRAPHYOFLAPALMASciComSupplementarymaterial.docx 